\title{
Ecology and Evolutionary Biology Must Make Room for BIPOC Scholars
}

\author{
Melanie Massey ${ }^{1}$, Suchinta Arif ${ }^{1}$, Catalina Albury ${ }^{1}$, and Victoria Cluney ${ }^{1}$ \\ ${ }^{1}$ Dalhousie University
}

December 9, 2020

\begin{abstract}
Research in ecology and evolutionary biology (EEB) plays a key role in understanding and intervening in our current environmental and climate crisis. Although anthropogenic stressors and climate change continue to disproportionately affect Black, Indigenous, and people of colour (BIPOC) individuals, their valuable scientific voices are shockingly underrepresented within EEB. To underscore this problem, we present a case study on EEB PhD graduates in the US (1994-2018), which illustrates that BIPOC scholars are significantly underrepresented in their cohorts. We recommend key steps that the EEB Academy should take to increase representation of BIPOC scholars in EEB, including anti-racism education and practice, increased funding opportunities, integration of diverse cultural perspectives, and a community-minded shift in PhDs. Importantly, this advice is directed at those who wield power in the Academy (e.g., funding agencies, societies, institutions, departments, and faculty), rather than BIPOC scholars already struggling against inequitable frameworks in EEB.
\end{abstract}

\section{Ecology and Evolutionary Biology Must Make Room for BIPOC Scholars}

Melanie D. Massey (melanie.massey@dal.ca)*1,2, Suchinta Arif ${ }^{1,2}$, (suchinta.arif@dal.ca), Catalina

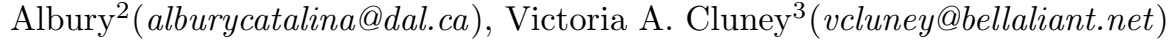

*Corresponding author

Tel: (647) 887-9629

${ }^{1}$ Author contribution was equal

${ }^{2}$ Dalhousie University, Department of Biology

Life Sciences Building,

1355 Oxford St. B3H 3Z1,

Halifax, Nova Scotia, Canada

${ }^{3}$ Wolastoqey Nation in New Brunswick

150-2 Cliffe St, E3A 0A1

Fredericton, New Brunswick, Canada

Running title: BIPOC scholars in EEB

Keywords: anti-racism, BIPOC, climate, ecology, EEB, evolution, outreach, two-eyed seeing, URM

Statement of authorship 
MDM and SA conceived the idea for this project. MDM and SA coordinated the drafting of the manuscript and all authors contributed to drafting the manuscript. SA collated the data and wrote the Supplemental Material. MDM created the figures. All authors edited the final manuscript and collaboratively discussed their perspectives throughout writing the manuscript.

\title{
Data accessibility statement
}

No new data were used in this manuscript; all data used are publicly available from the US Survey of Earned Doctorates Data Tables (Data available from the National Science Foundation: https://ncses.nsf.gov/pubs/nsf20301/).

Type of article: Viewpoint

Counts: Abstract words (146), main text words (2044), references (48), figures (1), text boxes (0)

\begin{abstract}
Research in ecology and evolutionary biology (EEB) plays a key role in understanding and intervening in our current environmental and climate crisis. Although anthropogenic stressors and climate change continue to disproportionately affect Black, Indigenous, and people of colour (BIPOC) individuals, their valuable scientific voices are shockingly underrepresented within EEB. To underscore this problem, we present a case study on EEB PhD graduates in the US (1994-2018), which illustrates that BIPOC scholars are significantly underrepresented in their cohorts. We recommend key steps that the EEB Academy should take to increase representation of BIPOC scholars in EEB, including anti-racism education and practice, increased funding opportunities, integration of diverse cultural perspectives, and a community-minded shift in PhDs. Importantly, this advice is directed at those who wield power in the Academy (e.g., funding agencies, societies, institutions, departments, and faculty), rather than BIPOC scholars already struggling against inequitable frameworks in EEB.
\end{abstract}

Black, Indigenous, and people of colour (BIPOC) communities are disproportionately affected by the impacts of anthropogenic stressors and climate change (IPCC, 2014). Already, for example, increased rates of extreme weather events and air pollution negatively affect the health of many Black Americans (Sarfaty et al. 2014) and threaten the food security of Northern Indigenous populations (Ford 2009). Such disproportionate effects are a consequence of the exacerbation of existing societal inequalities, largely due to the intersection of racial inequality and socioeconomic disparity (Cutter \& Finch 2014). Furthermore, the vulnerability of individuals to the impacts of climate change is strongly linked to the strength of their political voices - and through voting suppression, incarceration, and wealth inequality, BIPOC voices have, and continue to be, systematically silenced (Brookset al. 2005; Richomme 2014).

Given the disproportionately large and negative effects of ongoing environmental and climate crises on BIPOC communities, we and others (Halsey et al. 2020; Tseng et al. 2020) are concerned by the lack of diversity that we see in our PhD cohorts in Western universities. As EEB (ecology and evolutionary biology) students, scientists, and technicians, we are at the forefront of developing knowledge that tackles issues of biodiversity, ecosystem function, conservation, and human health, among numerous other global problems. PhD graduates in particular hold unique positions in society; they are be responsible for producing primary EEB research, for creating or influencing environmental policy, and represent the pool of candidates from which advanced EEB educators emerge. Further, compelling evidence indicates that racial diversity itself is beneficial to the quality, quantity, and impact of research (Hong \& Page 2004; Freeman \& Huang 2014; Hofstra et al. 2020). In light of current ecological crises and widespread concerns regarding racial representation in Academia, there is a clear and urgent need to leverage and include the voices of BIPOC scholars in EEB research.

\section{Representation of BIPOC Ph.D. earners remains low in EEB}

As a case study of BIPOC PhD representation, we looked at annual data of EEB PhDs awarded to US citizens and permanent residents from the National Science Foundation's (NSF) Survey of Earned Doctorates 
(Data available from the NSF: https://ncses.nsf.gov/pubs/nsf20301/; seeSupplementary Methods). The data shows a continued trend of low BIPOC representation through time (Fig. 1a), which even lags behind the low BIPOC representation seen in STEM in general (Supp. Fig. 1S). The number of PhDs earned by Black, Indigenous, Hispanic, and Asian individuals remain consistently and substantially lower than that of their white peers. Notably, Indigenous scholars earn an average of fewer than $10 \mathrm{PhDs}$ per year (Fig. 1a). In total, white scholars earned nearly seven times the number of EEB PhDs of all BIPOC scholars combined from 1994 to 2018. When adjusted for racial population size, BIPOC scholars remain under-represented, whereas white scholars are moderately and consistently over-represented (Fig. 1b). Except for a notable boom in PhDs earned by Asian scholars in the mid-1990's, in most years all BIPOC scholars fall under the line of 'fair representation' (Fig. 1b). Hispanic and Black scholars are the least represented, and have not been fairly represented at any time between 1994 to 2018 (Fig. 1b).

For nearly a quarter-century, as the effects of anthropogenic climate change have tangibly intensified, we find that, paradoxically, the pool of advanced knowledge holders has not diversified to represent the communities most negatively affected. White scholars continue to make up the overwhelming bulk of all $\mathrm{PhD}$ graduates in EEB, and are consistently over-represented when adjusted for population size. We affirm our personal observations that EEB is particularly lacking in diversity; a discouraging fact, considering that EEB-related challenges continue to disproportionately impact BIPOC communities in North America and elsewhere.

\section{Actionable items for the EEB Academy}

BIPOC scholars face numerous barriers tied to systemic racism that can influence their recruitment, retention, and success in EEB. These include, but are not limited to: discrimination (Singh 2018; Eatonet al. 2020), financial barriers (Wanelik et al. , 2020), and feelings of isolation within EEB (O'Brien et al. 2020). BIPOC researchers as individuals can take specific actions to strengthen their personal resilience to these barriers within the EEB Academy; these actions have been previously addressed (Halsey et al. 2020; Tsenget al. 2020). Here, we build upon recommendations for individual action by focusing on steps that can be taken by larger organizational bodies (funding agencies, societies, institutions, departments, faculty) - i.e., those that wield systemic power in the Academy - that are intended to increase BIPOC representation and equity in EEB.

\section{Increase anti-racism education and practices}

Promoting BIPOC representation in EEB requires that larger organizational bodies move beyond diversity statements and commit to active and ongoing anti-racism work. This is an essential first step, as diversity initiatives are unlikely to lead to equity in higher education if the underlying problems of systemic racism continue to create hostile environments that limit retention and success for BIPOC scholars (Smith 2002; Puritty et al. 2017). We assert that it is the responsibility of organizational bodies and the individuals within, especially white individuals in leadership and supervisory roles, to commit to ongoing education on racial inequality (within EEB, higher education, and broader society), and overcome their own conscious and unconscious racial biases.

Anti-racism training could start with institutional or organizational equity, diversity, and inclusion (EDI) workshops and seminars (Walton \& Cohen 2011; Bezrukova et al. 2012), and self-education with best-practice guidelines for anti-racism (e.g., Chaudhary \& Berhe 2020). Importantly, funding agencies, institutions and departments should ensure accountability in attendance and adherence to this anti-racism work. For example, funding agencies or tenure committees may require that faculty applicants define challenges to EDI in their field, and explain steps the applicant has taken to remove these barriers (e.g., Natural Sciences and Engineering Research Council, n. d.). Ultimately, anti-racism education and practice will lead to the informed adoption of other strategies that promote BIPOC representation in EEB.

Make EEB financially accessible and attractive

Another key method for making PhD programs more accessible and attractive to BIPOC scholars is through 
increased funding opportunities. BIPOC students are more likely than their white peers to come from financially disadvantaged backgrounds (Estrada et al. 2016), and low PhD stipends may discourage promising BIPOC scholars from pursuing graduate studies in EEB (Brazziel \& Brazziel 2001). Increased funding in the form of scholarships and grants increases access and achievement rate of racialized students from lowincome backgrounds (Ononye \& Bong 2018), and is a proven strategy that has, for example, increased women representation in STEM (Buzzetto-More et al. 2010). Importantly, existing funding programs need to be modified to include intersectional structures that specifically target BIPOC scholars, as, for example, programs directed at broad inclusion can still favor white women (Huntet al. 2012).

Funding opportunities for BIPOC scholars can come from all levels of organization of the Academy. Departments and principal investigators should ensure their BIPOC graduate students are well-funded, both through base stipends and by assisting students with grant applications. Funding agencies should increase the targeted funding available to BIPOC students to support their access to and achievement within EEB. Societies should create BIPOC-focused awards and grants aimed at visibility (e.g., Weir 2020). Last, we recommend that EEB experiences critical to the development of successful EEB graduate students (e.g. , summer projects, fieldwork, internships) be well-funded, rather than unpaid or underpaid, to promote participation of BIPOC students from financially disadvantaged backgrounds (Fournier and Bond 2015; National Academies of Sciences, Engineering, and Medicine 2017).

Diversify scientific perspectives

Although Western paradigms dominate how we see science, there are many ways that individuals navigate science based on their varying cultural and philosophical foundations that must also be considered (e.g. , Cech et al. 2017). In EEB, inclusion of non-Western knowledge could include the adoption of philosophies such as Etuaptmumk (Mi'kmaw for "Two-Eyed Seeing"), an important framework used to promote the coexistence of Western and Indigenous paradigms (Barlettet al. 2012). For example, integrating Western and Indigenous knowledge systems to assess ecosystem health has produced more complex and historically informed assessments of changes in ecosystem quality (Mantyka-Pringle et al. 2017). This has been achieved by incorporating non-traditional environmental indicators, as well as Indigenous culturally transmitted knowledge of change (Mantyka-Pringleet al. 2017). In addition to more comprehensive research (Mistry \& Berardi 2016; Kutz \& Tomaselli 2019; Reid et al. 2020),Etuaptmumk has led to greater retention and success of Indigenous students in STEM (Osborne 2016; Michie et al. 2018), and better preparation in meeting the needs of vulnerable Indigenous communities (Huntington 2000; Mistry and Bernardi 2016; McKivett et al.2020); these benefits should be widely harnessed within EEB research and education.

More broadly, inclusion of diverse perspectives in EEB can occur through inclusion and amplification of the voices of EEB members from different cultural backgrounds (Chaudhary \& Berhe 2020), increased engagement with BIPOC communities impacted by ecological issues (Adams et al. 2014), and welcoming and celebrating non-traditional views or methods within labs and departments. Recent initiatives have facilitated these goals, and serve as excellent examples of how to foster and fund BIPOC collaborations and communities of BIPOC researchers. These initiatives include the creation of BIPOC-focused networks such as EEB PoC (El-Sabaawi et al. 2020) or \#EntoPoC (Goodman n. d.), as well as popular Twitter events including \#BlackBirdersWeek and \#BlackMarineScienceWeek. In addition to leading to more impactful and nuanced research (Hofstra et al. 2014; Reid et al. 2020), cultivating an atmosphere that values and utilizes diverse perspectives creates a stronger sense of belonging that combats feelings of isolation for BIPOC graduate students (O'Brien et al. 2018).

Re-evaluate traditional Ph.D. roles and responsibilities

Finally, the Academy should consider re-evaluating the traditional roles and responsibilities of $\mathrm{PhD}$ students. Academia is often perceived as a route to an individualistic career, ultimately providing rewards of achievement and power. However, students from BIPOC backgrounds can have stronger community-oriented cultures and career interests than their white peers (O'Brien et al, 2016; Smith et al. 2014; Purrityet al. 2017). In the current "publish or perish" climate of Academia, we leave little room for scholars to cultivate 
a sense of community. Creating more space in a $\mathrm{PhD}$ for community work, whether through integrative projects (e.g. , sustainability work with benefits to local communities), public outreach (e.g. , EEB outreach programs targeting BIPOC youth), teaching, or participation in student societies, may attract and retain more BIPOC talent (Fuestinget al. 2017; Puritty et al. 2017), while simultaneously being a healthy change to the current expectations of a $\mathrm{PhD}$ (Nature 2019). These changes can have downstream impact as well: community leadership from BIPOC PhD scholars themselves can in turn encourage the next generation of BIPOC students to enter EEB, as same-race role models significantly increase BIPOC students' interest in pursuing graduate studies in EEB (O'Brien et al. 2020).

Increased recognition of community work from funding agencies, especially when reaching underrepresented communities, as well as compensation from institutions and societies for such work, can facilitate and reward BIPOC scholars who choose to give back to their communities. Our Diversity of Nature (DoN) program (Massey et al.2020) is one example of graduate student-led community work. Here, BIPOC graduate students lead EEB field camps and in-school workshops targeting local BIPOC secondary students. This program is funded by various offices within our institution, EEB societies, and a national funding agency. Support, recognition, and funding from these larger organizational bodies has allowed us to create a sustainable program where BIPOC youth are encouraged to pursue EEB through racialized role models (Syed et al. 2011; O'Brien et al. 2020) and positive ecological experiences (Armstrong et al. 2007). At the same time, DoN has allowed us to take part in meaningful, financially compensated EEB community outreach, making for a more holistic and rewarding $\mathrm{PhD}$ experience.

\section{Final remarks}

In science, racial diversity benefits the quality, quantity, and impact of discoveries. However, there are moral obligations beyond the immediate benefit of diversity to science to include the voices of those who will continue to be most affected by our ongoing environmental and climate crises. Racially diverse communities and broader society will ultimately be the beneficiaries of efforts to achieve fair representation of BIPOC scholars, and we assert that this push must ultimately come from those who wield power in the Academy. The immediacy and immensity of the world's ecological problems and environmental problems demand that EEB make room for BIPOC scholars.

\section{Acknowledgements}

This research was conducted in Mi'kma'ki, the ancestral and unceded territory of the Mi'kmaq People. We thank Dr. Jeffrey Hutchings, Alana Westwood, Loay Jabre, Noor Youssef, and J. Scott McCain for their helpful comments on early drafts of this manuscript. This work was funded by a Fathom Fund grant awarded to Catalina Albury, Suchinta Arif, and Melanie D. Massey by the Marine Environmental Observation and Prediction Network.

\section{References}

Adams, M., Carpenter, J. A., Housty, D., Neasloss, P. C., Service, J., Walkus, J., et al. (2014). Toward increased engagement between academic and indigenous community partners in ecological research.Ecol. Soc. , 19(3), 5

Armstrong, M., Berkowitz, A., Dyer, L., \& Taylor, J. (2007). Understanding why underrepresented students pursue ecology careers: a preliminary case study. Front. Ecol. Environ ., 5(8), 415-420

Barlett, C., Marshall, M., \& Marshall, A. (2012). Two-eyed seeing and other lessons learned within a co-learning journey of bringing together Indigenous and mainstream knowledges and ways of knowing. $J$. Environt. St. Sci. , 2(4), 331-340.

Bezrukova, K., Jehn, K. A., \& Spell, C. S. (2012). Reviewing diversity training: Where we have been and where we should go. Acad. Manag. Learn. Edu. , 11(2), 207-227.

Brazziel, M. \& Brazziel, W. (2001). Factors in decisions of underrepresented minorities to forego science and engineering doctoral study: a pilot study. J. Sci. Educ. Tech., 10, 273-281. 
Brooks, N., Adger, W. N., \& Kelly, P. M. (2005). The determinants of vulnerability and adaptive capacity at the national level and the implications for adaptation. Glob. Env. Change, 15(2), 151-163.

Buzzetto-More, N. A., Ukoha, O. \& Rustagi, N. (2010). Unlocking the barriers to women and minorities in computer science and information systems studies: Results from a multi-methodological study conducted at two minority serving institutions. J. Inf. Technol. Educ. Res.,9, 115-131.

Cech, E., Metz, A., Smith, J., \& deVries, K. (2017). Epistemological dominance and social inequality: Experiences of Native American science, engineering, and health students. Science, Technology \& Human Values , 42(5), 743-774.

Chaudhary, V. \& Berhe, A. (2020). Ten simple rules for building an antiracist lab. PLoS Comput. Biol., $16, \mathrm{e} 1008210$.

Cutter, S. L. \& Finch, C. (2008). Temporal and spatial changes in social vulnerability to natural hazards. Proc. Natl. Acad. Sci. U. S. A., 105, 2301-2306.

Eaton, A. A., Saunders, J. F., Jacobson, R. K., \& West, K. (2020). How gender and race stereotypes impact the advancement of scholars in STEM: Professors' biased evaluations of physics and biology post-doctoral candidates. Sex Roles, 82(3-4), 127-141.

El-Sabaawi, R., Kantar, M., Moore, T., Pantel, J., Tseng, M., \& Ware, J. (2020). The EEB POC Project. Limnography and Oceanography Bulletin , 29(3), 97 - 99.

Estrada, M., Burnett, M., Campbell, A., Campbell, P., Denetclaw, W., Gutierrez, C., et al. Improving underrepresented minority student persistence in STEM. CBE: Life Sci. Educ ., 15(3), es5

Ford, J. D. (2009). Vulnerability of Inuit food systems to food insecurity as a consequence of climate change: a case study from Igloolik, Nunavut. Reg. Environ. Chang ., 9(2), 83-100..

Fournier, A. \& Bond, A. 2015. Volunteer field technicians are bad for wildlife ecology. Wildl. Soc. Bull., $39(4), 819-821$.

Freeman, R. B., \& Huang, W. (2014). Collaboration: Strength in diversity. Nat. News , 513(7518), 305.

Goodman, A. (N. d.) Entomologists of Color. Available at: [https://www.entopoc.org/]. Last accessed 03 December 2020.

Halsey, S. J., Strickland, L. R., Scott-Richardson, M., Perrin-Stowe, T. \& Massenburg, L. (2020). Elevate, don't assimilate, to revolutionize the experience of scientists who are Black, Indigenous and people of colour. Nat. Ecol. Evol. $4,1291-1293$.

Hofstra, B., Kulkarni, V., Galvez, S., He, B., Jurafsky, D., \& McFarland, D. (2020). The diversity-innovation paradox in science.PNAS , 117(17), 9284-9291.

Hogue, M. (2018). Dropping the "T" from CAN'T: enabling Aboriginal post-secondary success in science and mathematics. JCharlton Press, Vernon, pp. (1-199).

Hong, L. \& Page, S. (2004). Groups of diverse problem solvers can outperform groups of high-ability problem solvers. PNAS , 101(46), 16385-16389.

Hunt, V. H., Morimoto, S., Zajicek, A. \& Lisnic, R. (2012). Intersectionality and dismantling institutional

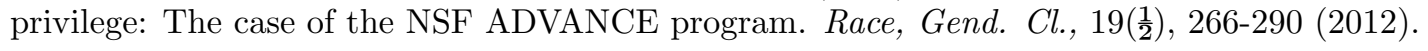

Huntington, H. (2000). Using traditional ecological knowledge in science: Methods and applications. Ecol. Appl. , 10(5): 1270-1274.

IPCC. (2014). Impacts, Adaptation, and Vulnerability. In: (Climate Change 2014 ). \{[eds.] Field, C. B. et al. ) 1132 pp. Cambridge University Press, Cambridge, UK, pp. 1-1132.

Kutz, S. \& Tomaselli, M. (2019). "Two-eyed seeing" supports wildlife health. Science, 364(6446), 1135-1137 
Mantyka-Pringle, C., Jardine, T., Bradford, L., Bharadwaj, L., Kythreotis, A., Fresque-Baxter, J. et al. (2017). Bridging science and traditional knowledge to assess cumulative impacts of stressors on ecosystem health. Environ. Int., 102, 125-137.

Massey, M. D., Arif, S., \& Albury, C. (2020). Diversity of Nature . Available at: [https://www.diversityofnature.com/] Last accessed 03 December 2020.

McKivett, A., Hudson, J., McDermott, D., Paul, D. (2020). Two-eyed seeing: A useful gaze in Indigenous medical education research.Med. Edu., 54(3), 217-224.

Michie, M., Hogue, M., Rioux, J. (2018). The application of both-ways and two-eyed seeing pedagogy: reflections on engaging and teaching science to post-secondary Indigenous students. Res. Sci. Ed., 48, 12051220

Mistry, J., Berardi, A. (2016). Bridging indigenous and scientific knowledge. Science, 352(6291), 1274-1275.

Nature, no authors listed. (2019). The mental health of PhD researchers demands urgent attention. Nature , 575(7782), 257-258.

National Academies of Sciences, Engineering, and Medicine. (2017).Undergraduate Research Experiences for STEM Students: Success, Challenges, and Opportunities. The National Academies Press, Washington, DC, USA.

National Science Foundation. (N. d.) Doctorate Recipients from US Universities . NSF. Available at: https://ncses.nsf.gov/pubs/nsf20301/

Natural Sciences and Engineering Research Council. (N. d.). Guide for Applicants: Considering equity, diversity and inclusion in your application. Available at: [https://www.nserc-crsng.gc.ca/_doc/EDI/Guide_for_Applicants_EN.pdf]. Last accessed 03 December 2020.

O'Brien, L. T., Bart, H. L. \& Garcia, D. M. (2020). Why are there so few ethnic minorities in ecology and evolutionary biology? Challenges to inclusion and the role of sense of belonging. Soc. Psychol. Educ.23, 449-477.

Ononye, L. \& Bong, S. (2018). The study of the effectiveness of scholarship grant program on low-income engineering technology studentsJ. STEM Educ. Innov. Res. 18, 26-31.

Puritty, C., Strickland, L., Alia, E., Blonder, B., Klein, E., Kohl, M.,et al . (2017). Without inclusion, diversity initiatives may not be enough. Science, 357(6356): 1101-1102

Reid, A. J., Eckert, L., Lane, J., Young, N., Hinch, S., Darimont, C. et al. (2020). Fish Fish. "Two-Eyed Seeing": An Indigenous framework to transform fisheries research and management. In press (accepted). doi:10.1111/faf.12516

Richomme, O. (2014). Beyond equal rights: The persistence of ethno-racial inequalities in America. Revue LISA , 12 (7), Online.

Sarfaty, M., Mitchell, M., Bloodhart, B. \& Maibach, E. W. (2014). A survey of African American physicians on the health effects of climate change. Int. J. Environ. Res. Public Health, 11, 12473-12485.

Singh, G. (2018). Addressing discrimination and diversity in ecology is not just about implicit bias. Nat. Ecol. Evol. , 2, 584.

Smith, W. A., Altbach, P. G. \& Lomotey, K. (2002). The racial crisis in American higher education: Continuing challenges for the twenty-first century. State University of New York, New York, USA, pp (1-332).

Smith, J. L., Cech, E., Metz, A., Huntoon, M., \& Moyer, C. (2014). Giving back or giving up: Native American student experiences in science and engineering. Cult. Divers. Ethn. Min., 20(3), 413-429. 
Syed, M., Azmitia, M., Cooper, C. 2011. Identity and academic success among under-represented ethnic minorities: An interdisciplinary review and integration. J. Soc. Iss. , 67(3), 442-468.

Tseng, M., El-Sabaawi, R., Kantar, M., Pantel, J., Srivastava, D., \& Ware, J. (2020). Strategies and support for Black, Indigenous, and people of colour in ecology and evolutionary biology. Nat. Ecol. Evol., 4, $1288-1290$.

Walton, G. M., \& Cohen, G. L. (2011). A brief social-belonging intervention improves academic and health outcomes of minority students.Science, 331(6023), 1447-1451.

Wanelik, K. M., Griffin, J. S., Head, M. L., Ingleby, F. C., \& Lewis, Z. (2020). Breaking barriers? Ethnicity and socioeconomic background impact on early career progression in the fields of ecology and evolution. Ecol. Evol. , 10(14), 6870-6880.

Weir, L. (2020). CSEE BIPOC Resources Library Microgrants . Available at: [https://www.cseescee.ca/csee-bipoc-resources-library-microgrants/]. Last accessed 03 December 2020.

Figure and figure legend

Figure 1. a , Ecology and Evolutionary Biology (EEB) doctorates earned from 1994 - 2018 in the United States by race. Races are indicated by line colour: red (Asian), gold (Black), green (Hispanic), blue (Indigenous), and pink (White). b, Ratio of percent doctorates earned by year in Ecology and Evolutionary Biology (EEB) disciplines to percent population makeup in the United States by race. A value of 1 indicates there is an equal ratio of percent doctorate earners to percent of total United States population by race (black solid 'fair representation' line). Races are indicated by line colour: red (Asian), gold (Black), green (Hispanic), blue (Indigenous), and pink (White).
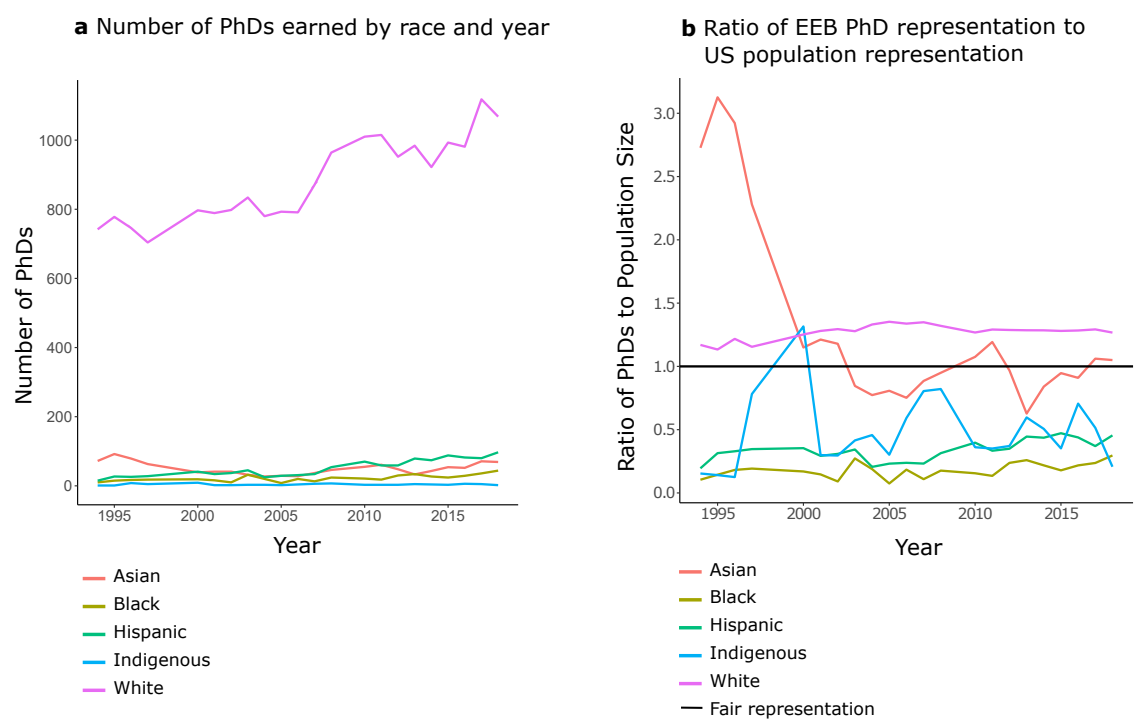